\title{
Knowledge and attitude towards cervical cancer among reproductive age group women in Gondar town, North West Ethiopia
}

Ayelign Mengesha ${ }^{1 *}$ (D) Anteneh Messele ${ }^{2}$ and Biruk Beletew ${ }^{3}$

\begin{abstract}
Background: Cervical cancer is the second most commonly diagnosed cancer and the third leading cause of cancer death in women worldwide. Nearly $83 \%$ of the world's new cases and $85 \%$ of all cervical cancer-related deaths occur in developing countries. It is primarily caused by human papilloma virus (HPV); a sexually transmitted pathogen that could be prevented with safe sexual practice and using vaccines among others.

The aim of the study was to assess the knowledge and attitude of reproductive age group women towards cervical cancer and its prevention in Gondar town.

Methods: A descriptive community based cross-sectional study was carried out. An interviewer-administered questionnaire was employed for data collection. A multistage sampling technique was employed to select the study participants. Descriptive statistics like frequency, mean and percentage were computed using SPSS version 20 software program.

Results: Seven hundred and seventy women $(n=770)$ participated with a response rate of 100\%. More than half, $(65.1 \%)$ of the participants claim hearing of cervical cancer. However, majority (> 80\%) of them lack knowledge that HPV is a causative agent of cervical cancer which is extremely worrying as the most important way to prevent cervical cancer is blocking HPV infection. Of those who had heard of it, only 107 (21.4\%) said they have heard about Pap smear test. From them, less than half, 47 (43.9\%) said that an apparently healthy woman should undergo the test at least three times in her life. This means in addition to the lack of information about the test, majority of those who had heard about it didn't know how many times they should have the test in their life. Overall, only 153 (19.87\%) of the participants were found having a good knowledge of cervical cancer and its prevention.

Conclusion: The overall knowledge of women towards cervical cancer was inadequate. On the other hand, those who had heard about it had a somewhat encouraging attitude. Mass media was the major source of information. But, any public health problem cannot be solved in isolation. Hence, initiating large-scale awareness campaigns is recommended.
\end{abstract}

Keywords: Cervical Cancer, Knowledge, Attitude, Reproductive age group women, Gondar town

\footnotetext{
* Correspondence: Ayelignmengesha59@gmail.com

${ }^{1}$ College of Health Sciences, Department of Nursing, Woldia University,

Weldia, Ethiopia

Full list of author information is available at the end of the article
}

(c) The Author(s). 2020 Open Access This article is distributed under the terms of the Creative Commons Attribution 4.0 International License (http://creativecommons.org/licenses/by/4.0/), which permits unrestricted use, distribution, and reproduction in any medium, provided you give appropriate credit to the original author(s) and the source, provide a link to the Creative Commons license, and indicate if changes were made. The Creative Commons Public Domain Dedication waiver (http://creativecommons.org/publicdomain/zero/1.0/) applies to the data made available in this article, unless otherwise stated. 


\section{Background}

Cervical cancer is a cancer of the cervix, the organ connecting the uterus and the vagina. It is predominantly caused by human papilloma virus (HPV) which is a sexually transmittable infection-causing pathogen. Therefore, effective interventions on prevention of HPV infections can prevent cervical cancer $[1,2]$.

Despite its preventable nature, globally cervical cancer is regarded as the third most common form of cancer among women after breast and colorectal cancer [3-5]. The women of poorer communities are mostly affected by the disease. It is evidenced that, approximately $83 \%$ of the world's new cases and $85 \%$ of all cervical cancer deaths reported are from developing countries [1].

The highest incidence rate of cervical cancer was observed in Guinea with nearly $6.5 \%$ of women developing cervical cancer before the age of 75 years. It affects women $<45$ years more than the other major cancers [5]. It is also the leading cause of cancer deaths in Eastern and Central Africa. Most of these deaths can be prevented through universal access to comprehensive cervical cancer prevention and control programs which can potentially reach all girls with HPV vaccination and all women who are at risk with screening and treatment for pre-cancer $[1,5,6]$.

Persistent infection with around 15 high-risk HPV types is the major risk factor for cervical cancer with HPV-16 and HPV-18 infections accounting for about $70 \%$ of the total cases. Multiple sexual partners, younger age at first sexual intercourse, early marriage, poor dietary habit, immune suppression, and cigarette smoking also serve as risk factors to the HPV persistent infection and progression to cancer $[1,6,7]$.

A study on global cancer transitions according to the human development index reveals that cervical cancer is estimated to be more common than both breast and liver cancer [8]. The study also suggests that rapid socioeconomic transition in many countries might reduce infection-related cancers. However, this might be replaced by an increasing number of new cases that are more associated with reproductive, dietary, and hormonal factors $[1,8]$.

The burden of cervical cancer is reasonably low in the developed countries of the world [9]. However, the situation is quite the reverse in developing countries. While the incidence is decreasing in the former, it is on the increase in the latter $[7,9,10]$. In most parts of SubSaharan Africa, South America, the Caribbean, and Southern Asia, cervical cancer is the leading cause of cancer death and premature death among women [7].

Sub-Saharan Africa is the region with the highest incidence of cervical cancer in the world with concomitant high mortality affecting women at their prime. This is a source of great concern considering the fact that cervical cancer is preventable and curable using currently available methods $[1,6]$. The onset of HIV/AIDS epidemic that is highest in the region has also raised the problem of cervical cancer to a serious level [6].

According to the 2009 world health organization report, cervical cancer ranks as the second most common cancer among women in Ethiopia [11]. The mean outpatient cost per patient for cervical cancer in Ethiopia is estimated to be $\$ 407.2$. The mean inpatient cost for hospitalized patients was also estimated to be $\$ 404.4$. The average direct inpatient cost was $\$ 329$ and for every additional day of inpatient hospital stay, there was an estimated daily incremental inpatient cost of $\$ 4.2$. This is very high and unimaginable for many patients to get treatment considering the socioeconomic status of the people [12].

Various studies in different countries show differences in women's knowledge and attitude regarding cervical cancer and its prevention. Unlike developed nations, in developing countries, women had a poor level of knowledge towards cervical cancer and its prevention [13-15]. A significant direct relationship was also found between women's knowledge and attitude towards cervical cancer and its prevention, and subsequent utilization of Pap smear test in some studies [16-18].

A very low rate of cervical cancer screening tests is reported across literatures in low and middle-income countries $[15,19-22]$. A study on health-seeking behavior of patients with cervical cancer in Ethiopia also revealed that women had a very low awareness of cervical cancer and they mostly prefer traditional remedies as a treatment option for the early stages of the disease. According to this study, the barriers to seeking any type of treatment identified were lack of awareness and access to proper health services. It also showed, women with cervical cancer were excluded from society and received poor emotional support [23].

Even though cervical cancer is a growing problem in Ethiopia in terms of morbidity, mortality, cost, and suffering, it has been neglected. To this day there is no national cancer control program and there is no cancer registration process. As a result, there is no morbidity and mortality data available to convince policymakers on this issue $[6,24]$.

Currently, Ethiopia is trying to expand cervical cancer screening programs and cancer treatment centers in different parts of the country [24]. Despite this effort studies on women's knowledge and attitude regarding cervical cancer in Ethiopia is limited. Hence, this study aimed to assess reproductive age group women's level of knowledge and attitude towards cervical cancer and its prevention in Gondar town.

\section{Methods}

Study area, design and period

A descriptive community based cross-sectional study was carried out in Gondar town. Gondar is the capital 
city of the North Gondar administrative zone of Amhara region, which is $738 \mathrm{~km}$ far from Addis Ababa, the capital city of Ethiopia. According to the 2007 census, Gondar has a total population of 206, 987, of whom 98,085 are males and 108,902 females living in 21 kebeles of the town. The study was conducted at four randomly selected kebeles found in the town from May 1-30, 2014 [25].

\section{Study population}

The study populations were all reproductive age group women who were living in four randomly selected kebeles of Gondar town.

\section{Eligibility criteria}

All reproductive age group women (15-49 years old) who were living in four randomly selected kebeles in Gondar town were included in the study.

\section{Sample size determination}

The sample size for this study was determined by using the single population proportion formula considering the assumptions: The proportion of reproductive age group women having adequate knowledge regarding cervical cancer being 50\% (Since there was no previous study in the study area). Level of significance $5 \%(\alpha=$ $0.05), Z \alpha / 2=1.96$ and margin of error $5 \%(d=0.05)$. Adding a $10 \%$ non- response rate and multiplying by 2 (design effect) the total sample size required for this study appeared to be 770 .

\section{Sampling technique}

A multistage sampling technique was employed to select the required samples. First, each of the 21 kebeles found in the town were taken as a cluster. In these clusters, four kebeles were selected by using the lottery method. Then, in these selected kebeles, the number of study participants was assigned proportionally. Finally, a systematic random sampling technique was employed to select study participants from the selected kebeles using house numbers as a unit of selection.

\section{Variables}

The outcome measures of this study were knowledge (which was classified as good and poor knowledge) and attitude (which in turn was also classified as favorable and unfavorable attitude) of reproductive age women towards cervical cancer. The independent variables included socio-demographic characteristics and related issues (age, religion, duration of stay in Gondar town, educational status, belief, occupation, income and exposure to mass media).

\section{Data collection technique and tools}

An adapted and structured, pretested, intervieweradministered questionnaire was employed to collect data from the participants [26]. First, the questionnaire was prepared in English and it was translated into Amharic, the local language, and then back to English to check its consistency. Each correct response received 1 point for knowledge and attitude questions and the scores were transformed into a percentage for interpretation of the results. The mean scores were utilized as a cut of point to describe the women's level of knowledge and attitude regarding cervical cancer and its prevention. One supervisor and two data collectors, who had BSc degree in nursing, were recruited to assist in the data collection process. The data collectors and the supervisor were trained for one day on how to facilitate the data collection process, prevent errors, keep privacy and confidentiality and other ethical issues.

\section{Data quality assurance}

To ensure the quality of data, the questionnaire was pretested on 5\% (39) of the sample size among selected females of reproductive age in Gondar town at kebele 11 from the unselected kebeles in the sampling process. The content and face validity of the questionnaire was done in previous studies [26, 27]. In this study, the Kuder-Richardson 20 (KR-20) reliability coefficient for the knowledge questions was 0.86 . On the other hand, the Cronbach's Alpha reliability coefficient for the attitude questions was 0.92 . All the necessary amendments were made on; the instructions, contents, order and grammatical issues. All data were checked for completeness, accuracy, clarity, and consistency by the supervisors and the principal investigator each night after the data were collected. Double data entry and validation were performed and the data were intensively cleaned before analysis.

\section{Data processing and analysis}

The data were coded and entered into a computer using Epi-data 3.1 Statistical program and were exported to SPSS Version 20 for further analysis. Data was processed and cleaned to minimize entry errors, and for outliers and missing values. Then, descriptive statistics like frequency, mean, and percent were computed for the study variables using SPSS version 20 software program. Participant's knowledge was analyzed and classified as good if a woman scores a result equal to or above the mean score level for questions used to measure knowledge and poor if a woman scores a result below the mean score level for questions used to measure knowledge. Similarly, participants were classified as having a favorable attitude if a woman scores a result equal to or above the mean score level and, those who answer below the mean score 
were classified as having an unfavorable attitude towards cervical cancer and its prevention. Finally, the result is summarized and presented using texts and tables.

\section{Results}

Socio demographic characteristics of participants

Seven hundred and seventy women $(n=770)$ participated in the study with a $100 \%$ response rate. Overall, $35.3 \%$ of women were within the age group of 24-32 years old. Most of the study participants (75.2\%) had lived in Gondar town for more than five years. Majority of the study participants $(86.8 \%)$ were Orthodox followers, followed by $11.7 \%$ Muslims. Among the study participants (54.5\%) were married. Virtually, 717 (93.1\%) participants were from the Amhara ethnic group. Of the participants, $82(10.6 \%)$ claim they can't read and write. The major proportion, 264 (34.3\%) had a monthly income of $<800$ Ethiopian Birr (Table 1).

\section{Participants knowledge regarding cervical Cancer and its prevention}

In this study, it is found that more than half, 501 (65.1\%) of the participants had heard about cervical cancer. Of those who had heard about cervical cancer, the largest number, 206 (41.1\%) had heard from mass media. The mean knowledge score was 3.21 (Standard deviation = 3.88 ) and the median was 2 . This study reveals that only $153(19.87 \%)$ of the participants had good knowledge regarding cervical cancer and its prevention.

The participants were asked whether they knew the risk factors that can lead to cervical cancer and from those who have heard about it (501), 299 (59.7\%) of them replied they didn't know the risk factors. Risk factors such as sexually transmitted disease, smoking, sex with multiple partners', family history of cervical cancer and others such as giving frequent births were asked. Majority, 408 (81.4\%) of the participants didn't know whether cervical cancer is caused by HPV or not.

Similarly, 401 (80\%) of the participants who had heard about it claim they didn't know the symptoms of cervical cancer. The common symptoms asked were: intra or post-coital bleeding, bleeding after menopause, persistent blood-stained vaginal discharge and lower abdominal pain. Concerning prevention and treatment, only $327(65.3 \%)$ and $214(42.7 \%)$ said that cervical cancer is preventable and curable respectively. Regarding screening tests, of the 501 participants who had heard about cervical cancer, only 107 (21.4\%) of them said they had heard about the Pap smear test. Of those who had heard about the Pap smear test, less than half, i.e. 47 (43.9\%) said that an apparently healthy woman should undergo a Pap smear test at least three times in her life (Table 2).

\section{Participants attitude towards cervical Cancer and its prevention}

In this study, it is found that the mean attitude score was 3.86. From the study participants who had heard about cervical cancer, 370 (73.9\%) replied, they believe that having multiple sexual partners is a risk factor for cervical cancer. More than half, 318 (63.5\%) believed that HIV positivity can increase the chance of getting cervical cancer. On the other hand, 433 (86.4\%) didn't believe that the use of oral contraceptive pills is a risk factor for cervical cancer.

Regarding smoking and early marriage, of those who had heard about it, 338 (67.5\%) and 366 (73.1\%) believed these conditions are a risk factor for cervical cancer respectively. In line with this, 442 (88.2\%) believed that cervical cancer is a major health problem for reproductive-age women and, 253 (50.5\%) believed that cervical cancer cannot be detected by early screening before symptoms appear. However, 457 (91.2\%) believed that, early detection of cervical cancer is good for treatment outcomes.

Similarly, 391(78\%) of those who had heard about it believed that cervical cancer is preventable. Regarding the prognosis, 264 (52.7\%) believed that cervical cancer is not curable and the remaining 237(47.3\%) believed it is curable. The study also reveals overall more than half, 448 (58.2\%) of the study participants had a favorable attitude towards cervical cancer and its prevention (Table 3).

\section{Discussion}

This study reveals that more than half, 501 (65.1\%) of the participants had heard about cervical cancer. This finding is consistent with a study in Qatar, Niger, and North Korea in which over 85,72 , and $62 \%$ claiming being aware of cervical cancer respectively. This reflects in terms of information there is encouraging evidence in these countries and Ethiopia. But, this information is not enough in creating knowledge which is reflected in the three studies and the present study [27-29]. In contrast, the result is higher than a study conducted in South Africa and another study in Ghana which shows that only 42.9 and $30.6 \%$ of the participants had heard of about cervical cancer respectively $[19,26]$.

Mass media was the major source of information (41.1\%), which is in line and far more than the South African study in which only $19 \%$ hearing about it from the media [26]. This difference might be due to differences in the study population in which the South African study included only university students who are mostly young aged and are not the main risk groups for cervical cancer and possibly not target groups for health education programs regarding it. However, the finding is in contrast with North Korea's study in which health care providers were the main source of information 
Table 1 Socio demographic characteristics of participants in Gondar town, Ethiopia, 2014 ( $n=770)$

\begin{tabular}{|c|c|c|c|}
\hline Variables & Response & Frequency & Percentage \\
\hline \multirow[t]{4}{*}{ Age } & $15-23$ & 255 & 33.1 \\
\hline & $24-32$ & 272 & 35.3 \\
\hline & $33-41$ & 149 & 19.4 \\
\hline & $42-49$ & 94 & 12.2 \\
\hline \multirow[t]{2}{*}{ Length of stay in the town } & $\leq 5$ years & 191 & 24.8 \\
\hline & $>5$ years & 579 & 75.2 \\
\hline \multirow[t]{5}{*}{ Religion } & Orthodox & 668 & 86.8 \\
\hline & Muslim & 90 & 11.7 \\
\hline & Protestant & 6 & 0.8 \\
\hline & Catholic & 1 & 0.1 \\
\hline & Others & 5 & 0.6 \\
\hline \multirow[t]{4}{*}{ Marital status } & Married & 420 & 54.5 \\
\hline & Single & 253 & 32.9 \\
\hline & Divorced & 64 & 8.3 \\
\hline & Widowed & 33 & 4.3 \\
\hline \multirow[t]{4}{*}{ Ethnicity } & Amhara & 717 & 93.1 \\
\hline & Tigray & 40 & 5.2 \\
\hline & Oromo & 11 & 1.4 \\
\hline & Others & 2 & 0.3 \\
\hline \multirow[t]{6}{*}{ Educational level } & Can't read and write & 82 & 10.6 \\
\hline & Read and write & 67 & 8.7 \\
\hline & Primary & 126 & 16.4 \\
\hline & Secondary & 184 & 23.9 \\
\hline & Preparatory & 61 & 7.9 \\
\hline & Diploma or degree & 250 & 32.5 \\
\hline \multirow[t]{6}{*}{ Occupation } & House wife & 196 & 25.5 \\
\hline & Student & 154 & 20.0 \\
\hline & Commercial sex worker & 7 & 0.9 \\
\hline & Governmental employee & 187 & 24.3 \\
\hline & Merchant & 149 & 19.4 \\
\hline & Others & 77 & 10.0 \\
\hline \multirow[t]{4}{*}{ Monthly income } & $\leq 800 \mathrm{ETB}$ & 264 & 34.3 \\
\hline & 800-1200 ETB & 169 & 21.9 \\
\hline & 1200-1600 ETB & 163 & 21.2 \\
\hline & $\geq 1600$ ETB & 174 & 22.6 \\
\hline
\end{tabular}

Key: ETB - Ethiopian birr

(69\%). This difference might be due to differences in media coverage between the countries, health service access and utilization levels. It might be also due to differences in the study population in which the North Korea study had included both urban and rural women's [29].

In this study, only $100(19.96 \%)$ of the participants who had heard about it claim they knew the symptoms of cervical cancer. This finding is in line with the North Korea's study in which less than $40 \%$ were aware of the symptoms of cervical cancer. This consistency might be due to the fact that, the overall level of knowledge between the two studies was inadequate [29]. It might be also due to the lack of health education programs regarding cervical cancer which is believed to be the problem of most developing countries [30].

Regarding the risk factors, of those who had heard about it only 153 (30.54\%) of the participants claim that sexually transmitted disease is a major risk factor for 
Table 2 Participants knowledge regarding cervical cancer in Gondar town, North West Ethiopia, 2014 ( $n=770$ for the first question and, 501 for the rest)

\begin{tabular}{|c|c|c|c|}
\hline Variables & Response & Frequency & Percentage \\
\hline \multirow[t]{2}{*}{ Heard about cervical cancer } & Yes & 501 & 65.1 \\
\hline & No & 269 & 34.9 \\
\hline \multirow[t]{2}{*}{ Know the risk factors for cervical cancer } & Yes & 202 & 40.3 \\
\hline & No & 299 & 59.7 \\
\hline \multirow[t]{7}{*}{ Knowledge on risk factors of cervical cancer } & Sexually transmitted disease & 153 & 75.7 \\
\hline & Smoking & 120 & 59.4 \\
\hline & Having multiple Sexual Partners & 135 & 66.8 \\
\hline & Poor dietary habit & 40 & 19.8 \\
\hline & Early marriage & 129 & 63.8 \\
\hline & Family history of cervical cancer & 19 & 9.4 \\
\hline & Others & 18 & 8.9 \\
\hline \multirow[t]{2}{*}{ HPV is a causative agent of cervical cancer } & Yes & 93 & 18.6 \\
\hline & No & 408 & 81.4 \\
\hline \multirow[t]{2}{*}{ Know common symptoms of cervical cancer } & Yes & 100 & 20.0 \\
\hline & No & 401 & 80.0 \\
\hline \multirow[t]{5}{*}{ Knowledge on the symptoms of cervical cancer } & Intra or Post coital bleeding & 58 & 58.0 \\
\hline & Bleeding after menopause & 38 & 38.0 \\
\hline & Persistent blood stained vaginal discharge & 73 & 73.0 \\
\hline & Lower abdominal pain & 33 & 33.0 \\
\hline & Others & 1 & 1.0 \\
\hline \multirow[t]{2}{*}{ Cervical cancer is preventable } & Yes & 327 & 65.3 \\
\hline & No & 174 & 34.7 \\
\hline \multirow[t]{2}{*}{ Cervical cancer is curable } & Yes & 214 & 42.7 \\
\hline & No & 287 & 57.3 \\
\hline \multirow[t]{2}{*}{ Heard about pap smear test } & Yes & 107 & 21.4 \\
\hline & No & 394 & 78.6 \\
\hline \multirow[t]{5}{*}{ If yes where did you hear about Pap smear for the first time? } & Relatives & 64 & 12.8 \\
\hline & Friends & 88 & 17.6 \\
\hline & Health workers & 123 & 24.6 \\
\hline & Mass media & 206 & 41.1 \\
\hline & Others & 20 & 4.0 \\
\hline \multirow[t]{3}{*}{ How many times should a healthy woman undergo pap smear test? } & Only once & 26 & 24.3 \\
\hline & Two times only & 34 & 31.8 \\
\hline & At least three times and above & 47 & 43.9 \\
\hline
\end{tabular}

cervical cancer. This is in line with the Qatar study in which only $24.8 \%$ having the same claim [27]. It is also in line with North Korea's finding which has found that only a very small proportion (3\%) knew that cervical cancer is predominantly the result of a sexually transmitted infection [29]. This consistency might again emerge from poor health care access and utilization levels and the lack of large-scale health education programs.

Similarly, only $93(18.6 \%)$ of the participants who had heard about it knew that HPV is a cause of cervical cancer which is very low compared to the South African and a study in Iraq in which around 48.5 and $36.9 \%$ of the respondents saying they knew that HPV causes cervical cancer respectively [26, 31]. 174 (34.7\%) said cervical cancer cannot be prevented which is much higher compared to the South African study in which only $1.2 \%$ of participants claiming cervical cancer cannot be prevented [26]. Both findings show how the knowledge of women in Gondar town is insufficient. These differences might be due to differences in access to 
Table 3 Participants attitude on test items towards cervical cancer in Gondar town, Ethiopia, 2014 ( $n=501)$

\begin{tabular}{|c|c|c|c|}
\hline Variables & Response & Frequency & Percentage \\
\hline \multirow[t]{2}{*}{ Believe having multiple sexual partners is risk factor for cervical cancer } & Yes & 370 & 73.9 \\
\hline & No & 131 & 26.1 \\
\hline \multirow[t]{2}{*}{ Believe cervical cancer is transmittable through sexual inter course } & Yes & 112 & 22.4 \\
\hline & No & 389 & 77.6 \\
\hline \multirow[t]{2}{*}{ Believe HIV positivity increases the chance of getting cervical cancer } & Yes & 318 & 63.5 \\
\hline & No & 183 & 36.5 \\
\hline \multirow[t]{2}{*}{ Believe use of oral contraceptive pill is a risk factor for cervical cancer } & Yes & 68 & 13.6 \\
\hline & No & 433 & 86.4 \\
\hline \multirow[t]{2}{*}{ Think that smoking is a risk factor for cervical cancer } & Yes & 338 & 67.5 \\
\hline & No & 163 & 32.5 \\
\hline \multirow[t]{2}{*}{ Think early marriage is a risk factor for cervical cancer } & Yes & 366 & 73.1 \\
\hline & No & 135 & 26.9 \\
\hline \multirow[t]{2}{*}{ Think cervical cancer is a major health problem for female of reproductive age group } & Yes & 442 & 88.2 \\
\hline & No & 59 & 11.8 \\
\hline \multirow[t]{2}{*}{ Think it is possible to detect cervical cancer with early screening before symptoms appear } & Yes & 248 & 49.5 \\
\hline & No & 253 & 50.5 \\
\hline \multirow[t]{2}{*}{ Think early detection of cervical cancer is good for treatment out come } & Yes & 457 & 91.2 \\
\hline & No & 44 & 8.8 \\
\hline \multirow[t]{2}{*}{ Believe cervical cancer is preventable } & Yes & 391 & 78.0 \\
\hline & No & 110 & 22.0 \\
\hline \multirow[t]{2}{*}{ Think it is possible to cure cervical cancer } & Yes & 237 & 47.3 \\
\hline & No & 264 & 52.7 \\
\hline
\end{tabular}

health care services, utilization, and health education programs among the countries. It may be also due to differences in the educational level of the study participants.

Participants were also asked to answer whether cervical cancer is preventable and curable. From those who had heard about it, 327 (65.3\%) and $214(42.7 \%)$ said that cervical cancer is preventable and curable respectively. This means from all participants, only 327 (42.5\%) and 214 (27.8\%) knew that cervical cancer is preventable and curable respectively. This is in line with the North Korea's study which revealed that majority of respondents (64\%) did not know that cervical cancer can be prevented [29]. This consistency might again emerge from the inadequate knowledge of participants between the two studies. It might also emerge from the lack of information about the prevention and treatment of cervical cancer. This reflects the hypothesis "the fewer people have the information about a certain problem the lower their knowledge".

Regarding screening tests, of the 501 participants who had heard about cervical cancer, only 107 (21.4\%) of them said they had heard about the Pap smear test. This finding is consistent with the Ghanaian study and with a study in Iraq in which only 3.3 and $28.79 \%$ claiming having heard of the Pap smear test and knowing that Pap smear is a test used to detect abnormal cervical cells in the respective studies $[19,31]$. However, it is very low compared to the Qatar study which revealed that $76 \%$ of women have heard about the Pap smear test. This discrepancy might be due to the study setting in which the Qatar study was institution-based and those who visit institutions are more likely to have information about the test [27]. It might be also due to differences in access and utilization of health care services in the two countries.

Of those who had heard about the pap smear test, only $47(43.9 \%)$ said that an apparently healthy woman should undergo a pap smear test at least three times in her life. This reveals that in addition to the lack of information about the Pap smear test, majority of those who had even heard about it didn't know how many times and/or how often they should have a Pap smear test in their life. This is in line with the Niger study and a study in Iran which shows that only 50.6 , and $44.3 \%$ being aware of cervical cancer screening tests respectively $[28,29]$.

The study had again revealed that overall only 153 (19.87\%) of the participants had good knowledge regarding cervical cancer and its prevention. This reflects even majority of those who had heard about cervical cancer didn't have sufficient knowledge regarding the disease. 
This is consistent with a study conducted on sexual health status and cervical cancer prevention among 250 Thai couples in which majority, (65.6\%) having a low level of knowledge about cervical cancer and its prevention [32]. This consistency might emerge from a lack of information about it. This might be also due to the lack of awareness creation programs regarding cervical cancer. Because chronic diseases like cancer are neglected and the major focus of government in most developing countries including Ethiopia is on infectious disease prevention [30]. It is also consistent with other studies across literatures in low and middle-income countries [14, 31, 33].

This study has also tried to assess the women's attitude, and of those (501) who had heard about cervical cancer, 370 (73.9\%) and 366 (73.1\%) believed that having multiple sexual partners and early marriage are risk factors for cervical cancer respectively. This may be attributed to the mere community belief that any unsafe sexual behavior is a risk for diseases. Because the community believes that people having multiple sexual partners always get punishment for their sins from God. Similarly, $442(88.2 \%)$ believed that cervical cancer is a major health problem for reproductive age group women. This may again be the result of a mere belief that any cancer is a serious health problem.

In line with the above finding, 248 (49.5\%) believed that cervical cancer can be detected by early screening before symptoms appear which is lower than the Qatar study which conducted among 500 women visiting primary health care, in which $312(62.4 \%)$ believed that cervical cancer can be detected with Pap smear test before symptoms appear. This difference might be due to the fact that, the Qatar study was institution-based and those who visit health institutions are more likely to get information about the Pap smear test [27].

Of the 501 who have heard about cervical cancer, 457 (91.2\%) believed that early detection of the disease is good for treatment outcomes. This is higher than the Qatar study in which, 64.8\% having the same belief [27]. This is quite surprising. But, it might be due to the community's perception that if a disease is once recognized by physicians, then the outcome is usually good. This in turn might be the result of inadequate knowledge of the community about the medical world [34].

Regarding the prevention and treatment outcome, $391(78 \%)$ believed that cervical cancer is preventable which is higher than a descriptive cross-sectional study conducted on the knowledge and attitude about cervical cancer in different countries at different levels of development in which $62 \%$ believed it was possible to prevent cervical cancer [35]. Less than half, 237 (47.3\%) believed that cervical is curable which is very much lower than the study in Qatar in which $412(82.4 \%)$ believed that cervical cancer is curable. This discrepancy could be due to the fact that in this study the knowledge of women about cervical cancer and its prevention was very low compared to the Qatar study [27].

This finding is also higher and in controversy with the finding in the knowledge section in which only 327 $(65.3 \%)$ and 214 (42.7\%) saying yes and the remaining no/don't know for the questions "is cervical cancer preventable and curable" respectively. This might emerge from those participants who said they don't know in the knowledge section for the questions but having a positive belief in the attitude section. Because, no and don't know were merged into "no" during the analysis phase.

The study also shows that more than half, 448 (58.2\%) of the study participants had a favorable attitude which is higher than the Qatar study which revealed that majority, 63.2\% having an unfavorable attitude regarding prevention and screening test of cervical cancer respectively [27] . This finding together with the other findings indicates, despite the low level of women's knowledge regarding cervical cancer and its prevention, their attitude is somewhat encouraging. It is also in line with other studies in Nepal and Iraq which reported that women had a positive attitude towards cervical cancer and Pap smear test $[14,33,36]$. But, the alarm here is that the result might emerge from mere optimism of study participants.

\section{Limitation}

This study was limited to Gondar town only due to constraints of time and funds. It would have been better if the rural women were included and differences in knowledge and attitude regarding cervical cancer were assessed among the two groups.

\section{Conclusion}

The overall knowledge of participants towards cervical cancer and its prevention was inadequate. The majority, $>80 \%$ of the participants lack knowledge that HPV is a causative agent of cervical cancer. This is extremely worrying as the most important way to prevent cervical cancer is blocking HPV infection. Furthermore, only $21.4 \%$ have heard about cervical cancer screening tests. Of them, less than half, 47 $(43.9 \%)$ said that an apparently healthy woman should undergo the test at least three times in her life. On the other hand, those who have heard about cervical cancer had a somewhat encouraging attitude.

Mass media was the major source of information regarding cervical cancer. However, any public health problem cannot be solved in isolation. Thus, governmental and non-governmental organizations and other concerned bodies need to work in collaboration to increase the level of women's general awareness of cervical cancer and its prevention. Besides, the government should work on collaborating health institutions with other sectors on awareness creation campaigns. 


\section{Abbreviations}

BSc: Bachelor of Science; ETB: Ethiopian birr; HIV: Human immunodeficiency virus; HPV: Human papilloma virus; Pap smear: Papanicolaou smear test; SPSS: Statistical package for social sciences

\section{Acknowledgments}

The authors would like to express our deepest gratitude to Gondar University for supporting this research. Our appreciation extends to the supervisor and data collectors. Our deepest gratitude also goes to those who participated in this study.

\section{Author's contributions}

AMK and AMB participated in all steps of the study from its commencement to writing. BB has participated in reviewing the paper, analysis, and interpretation of the data. All authors read and approved the final manuscript.

\section{Funding}

This study was supported by Gondar University. The university provided the necessary materials like pen, paper, copy, and printing services. But, it has not taken any part in the writing of the manuscript.

\section{Availability of data and materials}

Data supporting the conclusions of this article will be available on reasonable request to Ayelign Mengesha.

\section{Ethics approval and consent to participate}

Ethical clearance was obtained from Gondar College of medicine and health sciences. Then, a support letter was sent to the North Gondar health department to get permission and cooperation during the data collection process. Informed written consent was obtained from each study participant after a detailed explanation of the purpose and benefit of the study right before data collection. For those with age $<18$ years (15-17 years old), written consent was obtained from their parents/guardians and assent from them. Participation was voluntary and, each participant had signed on a statement of informed consent after completion of the interview. Privacy of the participants was kept during the interview and for the issue of confidentiality; the questionnaires remained anonymous and were not shared with anyone except the data collectors, the supervisor and investigators.

\section{Consent for publication}

Note applicable.

\section{Competing interests}

The authors declare that they have no competing interests.

\section{Author details}

${ }^{1}$ College of Health Sciences, Department of Nursing, Woldia University, Weldia, Ethiopia. ${ }^{2}$ School of Nursing and Midwifery, Department of Nursing, University of Gondar, Gondar, Ethiopia. ${ }^{3}$ College of Health Sciences, Department of Nursing, Woldia University, Weldia, Ethiopia.

\section{Received: 19 March 2019 Accepted: 16 January 2020} Published online: 11 February 2020

\section{References}

1. World Health Organization (WHO). Comprehensive Cervical Cancer Control. A guide to essential practice. Geneva: WHO; 2006.

2. Underwood SM, Ramsay-Johnson E, Dean A, Russ J, Ivalis R. Expanding the scope of nursing research in low resource and middle resource countries, regions, and states focused on cervical cancer prevention, early detection, and control. J Natl Black Nurses Assoc JNBNA. 2009;20(2):42.

3. Pontén J, Adami H-O, Bergström R, Dillner J, Friberg L-G, Gustafsson L, et al. Strategies for global control of cervical cancer. Int J Cancer. 1995;60(1):1-26.

4. Parkin DM, Pisani P, Ferlay J. Estimates of the worldwide incidence of 25 major cancers in 1990. Int J Cancer. 1999;80(6):827-41.

5. Arbyn $M$, Castellsagué $X$, de Sanjosé $S$, Bruni L, Saraiya M, Bray F, et al. Worldwide burden of cervical cancer in 2008. Ann Oncol. 2011;22(12):2675-86.
6. Louie KS, De Sanjose S, Mayaud P. Epidemiology and prevention of human papillomavirus and cervical cancer in sub-Saharan Africa: a comprehensive review. Tropical Med Int Health. 2009;14(10):1287-302.

7. Jemal A, Center MM, DeSantis C, Ward EM. Global patterns of cancer incidence and mortality rates and trends. Cancer Epidemiol Prev Biomark. 2010;19(8):1893-907.

8. Bray F, Jemal A, Grey N, Ferlay J, Forman D. Global cancer transitions according to the human development index (2008-2030): a populationbased study. The lancet oncology. 2012;13(8):790-801.

9. Torre LA, Bray F, Siegel RL, Ferlay J, Lortet-Tieulent J, Jemal A. Global cancer statistics, 2012. CA Cancer J Clin. 2015;65(2):87-108.

10. Forouzanfar MH, Foreman KJ, Delossantos AM, Lozano R, Lopez AD, Murray CJ, et al. Breast and cervical cancer in 187 countries between 1980 and 2010: a systematic analysis. Lancet. 2011;378(9801):1461-84.

11. World Health Organization Information Centre on HPV. Human papillomavirus and related cancers-World. Summary Report Update November 15, 2010. World Health Organization webpage. Available at: http://apps.who.int/hpvcentre/statistics/dynamic/ico/country_pdf/XWX. pdf?CFID=5706741\&CFTOKEN=92497064. Accessed 15 May 2014.

12. Hailu A, Mariam DH. Patient side cost and its predictors for cervical cancer in Ethiopia: a cross sectional hospital based study. BMC Cancer. 2013 Feb 8;13(1):69.

13. Al Meer, F.M., Aseel, M.T., Al Khalaf, J., Al Kuwari, M.G. \& Ismail, M.F.S. (2011). Knowledge, attitude and practices regarding cervical cancer and screening among women visiting primary health care in Qatar. EMHJ - eastern Mediterranean health journal, 17 (11), 855-861, 2011, https://apps.who.int/ iris/handle/10665/118198.

14. Shrestha J, Saha R, Tripathi N. Knowledge, attitude and practice regarding cervical cancer screening amongst women visiting tertiary Centre in Kathmandu. Nepal Nepal Journal of Medical Sciences. 2013;2(2):85-90.

15. Sancho-Garnier H, Khazraji YC, Cherif MH, Mahnane A, Hsairi M, El Shalakamy A, et al. Overview of cervical cancer screening practices in the extended Middle East and North Africa countries. Vaccine. 2013;31:G51-G7.

16. Al-Naggar R. Practice and barriers towards pap smear test from a public hospital in Malaysia. J Community Med Health Edu. 2012;2(132):2.

17. Batarfi N. Saudi Women's experiences, barriers, and facilitators when accessing breast and cervical Cancer screening services. Doctoral dissertation, University of York; 2012. Available at: https://pdfs.semanticscholar.org/565f/464c54 8078e81046d6c8818abf6f58b99fee.pdf. Accessed 12 May 2014.

18. Mirzaei-Alavijeh M, Karami-Matin B, Jalilian F, Rakhshani F, Mahboubi M, Emdadi S. Pap smear test promotion among women: an Educa-tional intervention based on theory of planned be-havior. Journal of biology and Today's World. 2014;3(4):100-3.

19. Innocentia Ebu N, Mupepi SC, Peter Siakwa M, Sampselle CM. Knowledge, practice, and barriers toward cervical cancer screening in Elmina, Southern Ghana. Available at: https://scholarworks.gvsu.edu/cgi/viewcontent. cgi?article=1049\&context=kcon_articles. Accessed, July 12, 2014.

20. Al Eyd GJ, Shaik RB. Rate of opportunistic pap smear screening and patterns of epithelial cell abnormalities in pap smears among women attending a teaching Hospital in Ajman, United Arab Emirates. Sultan Qaboos Univ Med J. 2012;22(1057):1-12.

21. El Banna N, Al Eyd G, Saeed RS. High-risk human papillomavirus infection among women with pap smear tests negative for intraepithelial lesions or malignancy. International Journal of Medicine and Public Health. 2014:4(1).

22. Al Rifai R, Nakamura K. Differences in breast and cervical cancer screening rates in Jordan among women from different socioeconomic strata: analysis of the 2012 population-based household survey. Asian Pac J Cancer Prev. 2015;16(15):6697-704.

23. Birhanu Z, Abdissa A, Belachew T, Deribew A, Segni H, Tsu V, et al. Health seeking behavior for cervical cancer in Ethiopia: a qualitative study. Int $J$ Equity Health. 2012 Dec 29;11(1):83.

24. Woldeamanuel YW, Girma B, Teklu AM. Cancer in Ethiopia. Lancet Oncol. 2013;14(4):289-90.

25. Federal Democratic Republic of Ethiopia Population census commission: Summary and Statistical report of the. Population and housing census. Addis Ababa: UNFPA. 2007;2008:9-10

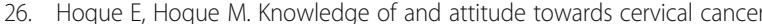
among female university students in South Africa. South Afr J Epidemiol Infect. 2009:24(1):21-4 
27. Al-Meer FM, Aseel MT, Al-Khalaf J, Al-Kuwari MG, Ismail MF. Knowledge, attitude and practices regarding cervical cancer and screening among women visiting primary health care in Qatar. Eastern Mediterranean Health Journal. 2011;17:855-61.

28. Owoeye IOG, Ibrahim IA. Knowledge and attitude towards cervical cancer screening among female students and staff in a tertiary institution in the Niger Delta. Int J Med Biomed Res. 2013;2(1):48-56.

29. Tran NT, Choe SI, Taylor R, Ko WS, Pyo HS, So HC. Knowledge, attitude and practice (KAP) concerning cervical cancer and screening among rural and urban women in six provinces of the democratic People's Republic of Korea. Asian Pac J Cancer Prev. 2011;12(11):3029-33.

30. Ali F, Kuelker R, Wassie B. Understanding cervical cancer in the context of developing countries. Ann Trop Med Public Health. 2012 Jan 1;5(1):3.

31. Hwaid AH. Knowledge and awareness of papillomavirus and cervical cancer among college students and health care workers women in Diyala. Iraq Am J Public Health Res. 2013;1(8):221-5.

32. Thiangtham W, Bennett T, Nuntaboot K. Sexual health status and cervical cancer primary prevention among Thai couples. J Public Health. 2010;1 (2): 22-30.

33. Saadoon OZ, Amin RM, Jadoo SAA. Factors influencing pap smear practice among primary school teachers in Diyala city. Iraq Malays J Public Health Med. 2014;14(1):19-28.

34. Padela Al, Killawi A, Heisler M, Demonner S, Fetters MD. The role of imams in American Muslim health: perspectives of Muslim community leaders in Southeast Michigan. J Relig Health. 2011;50(2):359-73.

35. Raychaudhuri S, Mandal S. Current status of knowledge, attitude and practice (KAP) and screening for cervical cancer in countries at different levels of development. Asian Pac J Cancer Prev. 2012;13(9):4221-7.

36. Abedian Z, Dormohamadi M. Investigating awareness, attitude and practice of women who referred to health centers of Mashhad city toward pop smear. The Iranian Journal of Obstetrics, Gynecology and Infertility. 2013;15(36):22-8.

\section{Publisher's Note}

Springer Nature remains neutral with regard to jurisdictional claims in published maps and institutional affiliations.

Ready to submit your research? Choose BMC and benefit from:

- fast, convenient online submission

- thorough peer review by experienced researchers in your field

- rapid publication on acceptance

- support for research data, including large and complex data types

- gold Open Access which fosters wider collaboration and increased citations

- maximum visibility for your research: over $100 \mathrm{M}$ website views per year

At $\mathrm{BMC}$, research is always in progress.

Learn more biomedcentral.com/submissions 